\title{
La cultura según los andaluces
}

En el marco del conocimiento de la cultura para una progresiva mejora de su gestión de cara al ciudadano en diferentes niveles, la Consejería de Cultura de la Junta de Andalucía y el Instituto de Estudios Sociales Avanzados del CSIC han puesto a disposición de los usuarios interesados los resultados de un barómetro de la cultura en la región, BACU 2010 (www.iesa.csic.es/archivo/barometrocultura 2010.pdf), que supone una aportación distinta a las habituales encuestas sobre hábitos culturales; una consulta dirigida a perfilar la idea que sobre cultura, sus matices y proyecciones, tiene la sociedad andaluza.

\section{Consenso cultural andaluz}

La principal deducción del BACU 2010 es que en Andalucia existe un consenso cultural que, en sus distintos niveles o grados, presenta a la andaluza como sociedad partícipe de una concepción contemporánea de la cultura, a la vez identificada con las principales expresiones de sus tradiciones colectivas. El principal consenso lo forma el reconocimiento mayoritario (entre el $75 \%$ y $95 \%$ ) de la mucha o bastante relación de la cultura con conceptos como las artes, música, letras, arquitectura o ciencia, viajes y deportes. Es relevante señalar que el barómetro ahora presentado tiene ya como referencia una primera oleada Ilevada a cabo en 2008, a partir de la cual se ha constatado la efectividad de los rasgos resultantes del estudio.
Como "eje" de esta idea andaluza de la cultura aparece el flamenco, en la medida en que concita su relación con la cultura de manera equilibrada en todos los tramos generacionales, situándose en la base del consenso primario aludido y a su vez coronando un segundo plano de consenso identitario en el que figuran procesiones, romerias, ferias y fiestas en general, así como los toros, oscilando entre el 50\% y $70 \%$ en su asociación con la cultura. Este consenso identitario cuenta con más respaldo entre jóvenes y mayores de 60 años que entre las edades intermedias, si bien con diferencias a veces sutiles. Por debajo, el BACU 2010 presenta un conjunto de conceptos de cultura que habla de los aspectos cambiantes, sea en ascenso como es el caso de internet o la publicidad, o en posiciones de desapego

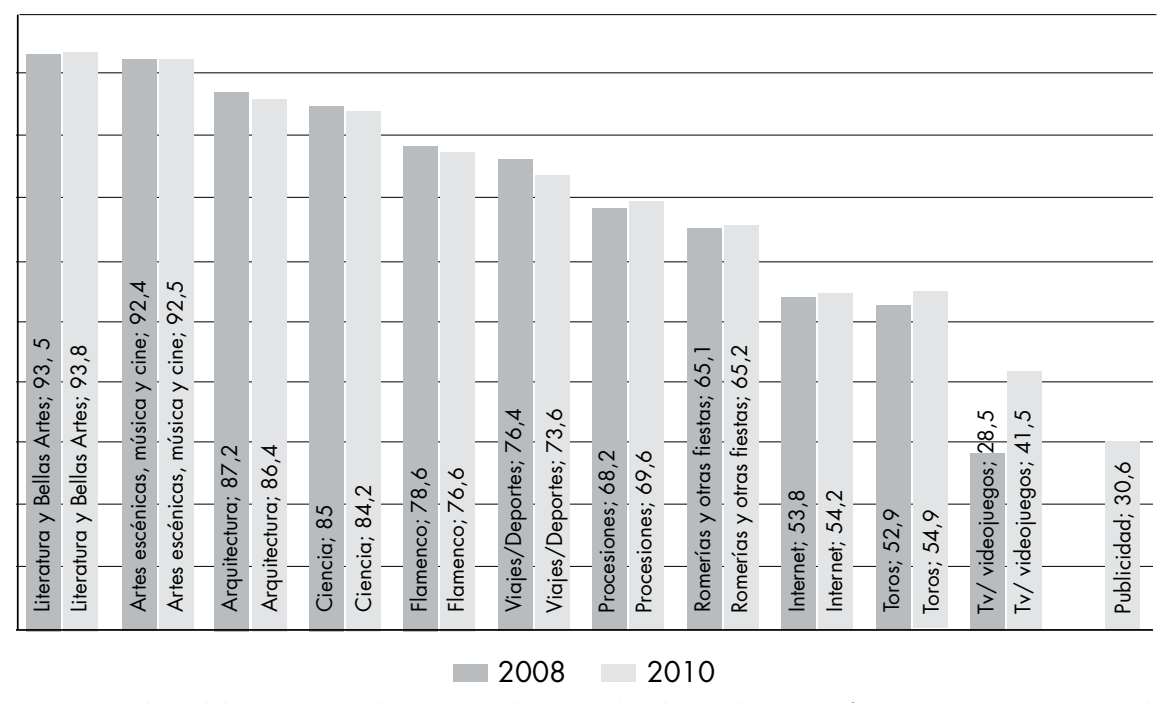

Porcentajes de andaluces encuestados que consideran que la relación de las manifestaciones artísticas y culturales seleccionadas con el término "cultura" es mucha o bastante (en 2008 y 2010). Fuente: IESA, BACU 2010 generalizado como la televisión o los videojuegos.

Sobre esa base, el 60\% de los andaluces identifica cultura con el hecho de tener una buena formación y muchos conocimientos, por encima del disfrute de las expresiones artísticas o incluso del respeto por las tradiciones. En consonancia, la formación es considerada mayoritariamente el principal factor para el desarrollo cultural de Andalucía. Hasta un 70\% de los consultados, en todo caso, manifiesta un interés específico por los temas culturales, porcentaje en el que coinciden a la hora de asegurar que la cultura les resulta útil en su vida cotidiana, singularmente en el ocio pero también en las relaciones sociales y en la vida familiar, aunque escasamente (en torno al 30\%) en el trabajo o los negocios.

Si cabe hablar de una conciencia relativa de la cultura andaluza, esta se caracterizaría por considerarla de un nivel algo más bajo que en el resto de España $y$, sobre todo, que en el resto de Europa; también porque ese nivel se considera menor en la escala local que en la regional y a su vez que en la española, si bien la oferta local de cultura es considerada buena o muy buena por el $42 \%$, y la oferta en el conjunto de Andalucía es valorada también positivamente por el 52\% (sobre todo por los más jóvenes), casi exactamente igual que la oferta existente en España. A ello hay que sumar que el conjunto de fiestas y celebraciones populares es tenido por el rasgo más representativo de la cultura andaluza (55\%), seguido de cerca por el patrimonio histórico (49\%).

Una mayoria que ronda el $60 \%$ se considera personas "algo cultas", junto a un $20 \%$ que se tiene por bastante o muy culto y otro $21 \%$ que se autocalifica como poco o nada cultos. En todo caso, en torno a un $70 \%$ de andaluces cree hoy dia que su nivel cultural es mayor o mucho mayor que el de sus padres, sensación que sólo desciende por debajo del 50\% entre los menores de 30 años. Y, a efectos per- 


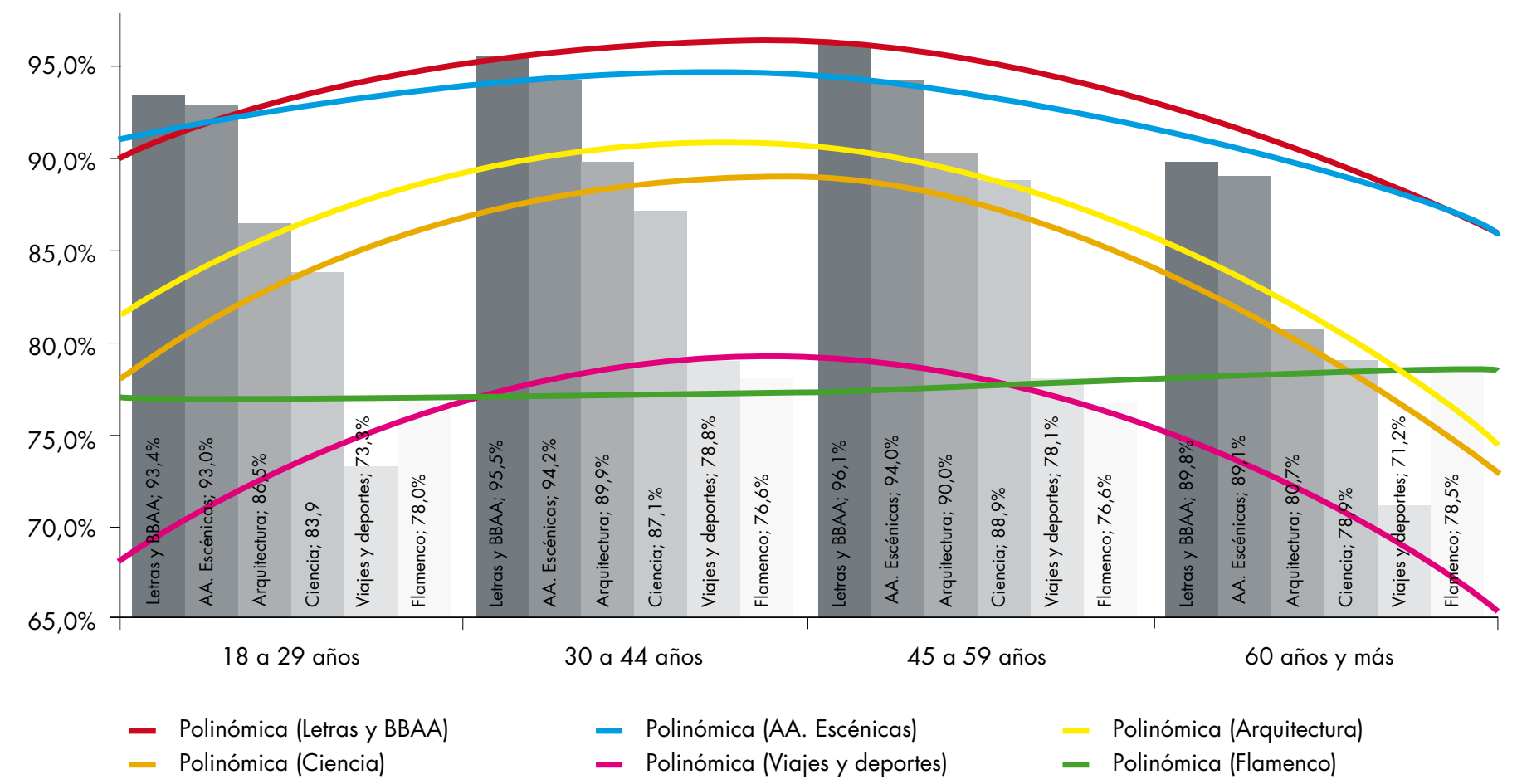

Componentes del consenso cultural primario en Andalucía según grupos de edades, medianas 2008-2010. Fuente: IESA, BACU 2008 y 2010

sonales, los andaluces se reparten entre quienes valoran la cultura como enriquecimiento personal (34\%) y quienes la estiman más como entretenimiento (35\%), quedando en un 20\% quienes la aprecian por los dos motivos y sólo en un 5\% quienes declaran que ni una ni otra cosa.

\section{Perspectiva de cambio}

La variación más significativa en los datos de 2010 respecto a dos años antes se refiere al soporte institucional y financiero. La idea generalizada en 2008 de que la cultura siempre debe contar con el apoyo estatal (80\%) ha descendido 24 puntos, hasta menos del 56\%, al tiempo que ha bajado un $11 \%$ la convicción de que las actividades culturales hayan de ser gratuitas; en 2010 más andaluces piensan que deben aportar al menos una parte de los costes. Es posiblemente el sintoma de cambio más neto entre los consultados con respecto a la función cultural en el espacio público, y en ello puede especularse que ha influido la coyuntura de crisis económica, pues el 59\% afirma que dicha coyuntura afecta negativamente a la cultura, si bien con el matiz de que ese impacto es similar al sufrido por otras actividades (el 71\% opina así).

El BACU 2010 refleja que, seguramente debido a la crisis, se ha producido un repliegue en el tiempo libre de los andaluces hacia el ámbito doméstico y hacia los espacios públicos, coincidente con un crecimiento notable de internet como recurso para informarse acerca de la cultura. Incluso podria hablarse de un incremento de la "conectividad" privada en Andalucia, levemente por encima de los datos disponibles para España proporcionados por el CIS prácticamente a la vez que el estudio del IESA. A destacar también que la justificación de los derechos de autor no llegue a concitar el 50\% de la opinión andaluza, en tanto sobrepasa ligeramente ese porcentaje la proposición de que no se paguen tales derechos por actividades "privadas". Todo lo cual apunta a una posible tendencia a primar la perspectiva personal sobre lo colectivo a la hora de enfocar la cultura.

Eso sí, las aportaciones del "mundo de la cultura" se consideran que son importan- tes para la sociedad (77\%), aunque menudee la idea de que ese mundo está algo o totalmente desconectado de la vida diaria (48\%), porque es cerrado y sabemos poco de él (55\%), o porque dicho mundo mira más por sus intereses que por los del conjunto social (62\%). A la hora de mirar hacia el entorno cultural, las comunidades autónomas de Madrid (43\%) y Cataluña (26\%) encabezan el ranking del interés cultural de los andaluces, y fuera de nuestras fronteras los paises europeos reciben con diferencia, en torno al 70\%, una atención sólo seguida de lejos por los latinoamericanos (23\%), y por un cierto repunte de los Estados Unidos y Canadá respecto a lo declarado en 2008.

En sintesis, los andaluces cuentan o contamos con un novedoso instrumento de cotejo de la idea de cultura que fluye y se conforma en una sociedad concreta, capaz de especificar matices, consensos o modificaciones en su estructura de conocimiento.

\section{Pedro A. Vives}

Colaborador del IESA-CSIC 